\title{
Tests of influence
}

\section{P.E. Bryant}

Beyond IQ: A Triarchic Theory of Human Intelligence.

By Robert J. Sternberg.

Cambridge University Press: 1985. Pp.411. Hbk £25, \$39.50; pbk £8.95, \$14.95.

A PARADOX touches the study of intelligence. The subject is controversial so controversial that it would be difficult to find even two psychologists who completely agree with each other on the nature of intelligence. Yet the psychologists' work in this area has had more impact outside the laboratory than anything else that has interested them, success which has merely increased the controversy. My own suspicion is that, if it were not for the obvious practical uses of these omnipresent tests, psychologists would have given up asking themselves about the underlying nature of intelligence as a far too abtruse and unrewarding question many years ago. But the very fact that the tests work, and that they seem to measure something which could reasonably be called intelligence, has posed a question which many have found impossible to resist investigating and trying to answer.

Robert Sternberg is the latest and almost certainly the most energetic in a long line of people who have devoted their time to attempting to say what intelligence means and what is responsible for intelligent behaviour. His approach is inclusive, and has become more so over the years. In this book, which is not his first on the subject, he sets out to combine three different approaches in what he calls a "triarchic" theory of intelligence. In order to understand why these three approaches have, on the whole, not been combined in the past, one needs to know something of the history of the study of intelligence.

It goes back to the first two pioneers of the intelligence test: Galton, whose tests were not a success, and Binet who, in contrast, produced the first effective intelligence test which has influenced every such test devised since then. The reasons for Galton's failure and Binet's success are important. Galton adopted a theoretical approach: he decided that intelligence consists of this and that ability and then produced tests to measure them. One test, for example, measured the speed of people's movements, another how well they named colours. These tests were certainly measures in the sense that different people produced different scores on them, but they did not measure intelligence. It soon turned out that they bore no relation to educational attainment, and that made it difficult to believe that they had anything to do with intellectual capacity.

Binet, too, had his theories, as Sternberg notes, but he did not let them play much part in his tests. His approach was prag- matic, and he had one clear guideline. Whatever intelligence is, he argued, it increases during childhood. So he only accepted tests which older children were more likely to answer correctly than were younger ones. This approach worked. Binet's test did predict reasonably well how children would manage at school, and every other intelligence test since then has had a strong, though never perfect, relation to educational achievements.

But this practical success left an arresting theoretical vacuum. The tests themselves did little to reveal the underlying nature of intelligence. In the following 50 years or so the main attempts to fill this gap were made by people who used factor analysis as their main tool and their answers were distinctly uninspiring. They looked rather like the first part of a cooking recipe; intelligence was held to consist of this factor and this one and so on, and there was no sense of a system that actually worked. Sternberg gives reasonably short shrift to these theories. He is concerned with the workings of intelligence.

This is not at all surprising since Sternberg comes from a tradition in psychology which developed quite separately from the intelligence testing movement and which originally had nothing to do with individual differences. The study of information processing is concerned with the underlying processes involved in taking in, remembering and coordinating information about the environment, and its subject matter goes from the simplest kind of remembering or attention through to complex logical processes such as making sophisticated analogies or drawing inferences. Sternberg has always argued that this is the stuff of intelligence, and most of his work has taken the form of forging links between studies of information processing and studies of differences in intelligence.

But now he thinks that this is not enough. His "triarchic" model is really a model of how to approach the question of intelligence rather than a fully fledged theory about intelligence. He argues that we need to know not only about the components of intelligence (the information processing involved) but also about the role of experience (particularly about the way that skills become automatic after a while) and, as well, about the context in which intelligent behaviour takes place. These three kinds of question are Sternberg's triarchy and the first half of the book is a convincing argument that all three are needed. In the second half he deals with particular problems which have always been closely associated with the study of intelligence, many of which - such as syllogisms and analogies - crop up a great deal in intelligence tests. His aim is to subject them to his triarchic approach, but here the analysis is often uneven though it is always very detailed. Sternberg's "componential"' leanings take over. There is little in this part of the book about either context or the effects of experience. Sternberg has more research to do on these two questions, but given his phenomenal productivity there seems little doubt that he will manage it.

In the end the proof of Sternberg's pudding will be the same as it was with Galton's and Binet's. His scheme will only influence people outside the world of psychology, and to a great extent within it too, if it manages to produce good, new tests. Only then can we be sure that his scheme transcends the laboratory in a way that Galton's so signally did not. Sternberg seems to recognize this when at the end of the book he suggests several ways of improving tests of intelligence. He should try these out. In the meantime he has written an attractive and valuable account of the long and successful enterprise which began so well with Binet and still seems to be in very good hands.

P.E. Bryant is Watts Professor of Psychology at the University of Oxford.

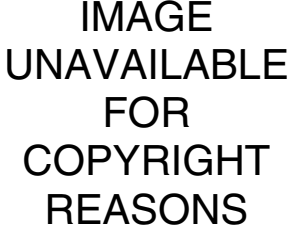

Upright education - the Geradhalter, an invention of a nineteenth-century educator, one Dr Schreber, intended to improve children's posture by discouraging them from slumping forward. Schreber used this and similar devices on his own children, one of whom was mentally deranged for most of his adult life. The illustration is taken from Robert Trivers's Social Evolution, published by Benjamin/Cummings. 